\title{
Interleukin-10 does not affect IL-1-induced interleukin-6 and metalloproteinase production in human chondrosarcoma cells, SW1353
}

\author{
JÜRGEN RADONS ${ }^{1}$, WERNER FALK ${ }^{2}$ and THOMAS E.O. SCHUBERT ${ }^{3}$ \\ ${ }^{1}$ Abteilung Hämatologie und Internistische Onkologie, ${ }^{2}$ Klinik und Poliklinik für Innere Medizin I, \\ ${ }^{3}$ Institut für Pathologie, Universität Regensburg, D-93053 Regensburg, Germany
}

Received August 23, 2005; Accepted October 14, 2005

\begin{abstract}
Cartilage repair by transplantation of autologous chondrocytes is an option when restoring functional joints. Control of chondrocyte function is thus required. Interleukin10 (IL-10) is a potent anti-inflammatory cytokine affecting the expression of a wide range of immune mediators in hematopoietic and non-hematopoietic cells. Previous studies indicated that IL-10 has therapeutic potential in the treatment of chronic inflammatory joint disorders such as rheumatoid arthritis and osteoarthritis. IL-10 has been found to be chondroprotective by down-regulating metalloproteinase expression and by inhibiting the synthesis of pro-inflammatory cytokines, such as IL-6, in immune cells. In contrast, the effects of IL-10 on chondrocytes are poorly understood and have to be identified with regard to their future clinical use. In this study, we investigated the effects of IL-10 on the expression of cartilage-degrading mediators in the human chondrosarcoma cell line, SW1353, after exposure to IL-1, a key mediator in cartilage and bone destruction. We found a strong induction of the pro-inflammatory cytokine, IL-6, in IL-1-exposed SW1353 cells. Surprisingly, IL-10 had no effect on IL-1-induced IL-6, pro-MMP1, and pro-MMP13 secretion. Although RT-PCR analyses demonstrated the expression of both receptor chains of the IL-10 receptor complex (IL-10R1 and IL-10R2), exposure of SW1353 to IL-10 did not lead to phosphorylation of STAT3, the major transcription factor induced by IL-10. This was not due to a defect in STAT3, because stimulation with IL-6 resulted in its phosphorylation. Failure of SW1353 cells to respond to IL-10 was consistent with a deficient surface expression of IL-10R1. From these
\end{abstract}

Correspondence to: Dr Jürgen Radons, Abteilung Hämatologie und Internistische Onkologie, Universität Regensburg, Franz-JosefStrauss-Allee 11, D-93053 Regensburg, Germany

E-mail: juergen.radons@klinik.uni-regensburg.de

Key words: IL-10, chondrocytes, STAT3, IL-10 receptor, IL-6, metalloproteinases, SW1353 results we conclude that IL-10 does not exert its chondroprotective character on chondrocytes directly. Furthermore, the unresponsiveness of chondrocytes towards IL-10 might explain the vulnerability of joint cartilage to inflammation.

\section{Introduction}

Articular cartilage lesions represent a common problem. It has been shown previously that almost two-thirds of arthroscopically examined knees harbour cartilage lesions (1). The same study demonstrated that $5 \%$ of arthroscopies in patients under the age of 40 years had a full-thickness cartilage defect. The treatment of chondral lesions is challenging because articular cartilage has a limited capacity to regenerate leading to further deterioration of the cartilage and finally osteoarthritis.

A variety of different techniques has been developed for the treatment of chondral lesions, including microfracturing $(2,3)$ and abrasion arthroplasty (4). Since these techniques only lead to the generation of fibrocartilage instead of normal hyaline cartilage (5), interest has focused on transplantation and grafting techniques, such as osteochondral allografts and autografts $(6,7)$ as well as autologous chondrocyte transplantation $(8,9)$, as an option to restore functional joints.

Interleukin-10 (IL-10) is an important immunomodulatory cytokine which has attracted attention because of its antiinflammatory properties. IL-10 is a pleiotropic cytokine playing an important role in regulating immune responses (for review see refs. 10,11). Its main biological functions appear to limit and terminate inflammatory responses, block pro-inflammatory cytokine secretion and regulate the differentiation and proliferation of several immune cells. In addition, the destructive activities of matrix metalloproteinases (MMPs) are limited by IL-10, as the cytokine does not only inhibit the expression of MMP2, MMP3, and MMP9, but also induces the production of tissue inhibitor of MMP (TIMP), TIMP1 $(12,13)$. As MMPs are involved in cartilage degradation in chronic inflammatory joint diseases such as rheumatoid arthritis (RA) and osteoarthritis, inhibition of these proteases by IL-10 may exert a chondroprotective action.

The anti-inflammatory potential of IL-10 has encouraged clinical trials for the treatment of chronic inflammatory diseases, including inflammatory bowel disease, psoriasis, and RA. Unfortunately, these efforts have met only limited 
success (14). How IL-10 mediates its function on the molecular level remains a matter of debate. The effects of IL-10 on chondrocytes are especially poorly understood and have to be identified with regard to their future clinical use, particularly in autologous chondrocyte transplantation. Therefore, in the present study, we aimed to investigate the effects of IL-10 on human chondrocytes in more detail. We demonstrated an unresponsiveness of the human chondrosarcoma cell line, SW1353, towards IL-10. This failure correlated with a defective expression of IL-10R1 on the plasma membrane and might explain the vulnerability of joint cartilage to inflammatory processes.

\section{Materials and methods}

Isolation of human chondrocytes. The cartilage used for primary cultures of healthy tissue was obtained from the joints of legs amputated because of trauma or vascular disease after obtaining approval from the local ethics committee. Chondrocytes were prepared from macroscopically normal cartilage samples by enzymatic digestion, essentially as previously described (15). Isolated chondrocytes were plated in $75-\mathrm{cm}^{2}$ tissue culture flasks in Ham's F-12/DMEM (1:1) supplemented with $10 \%$ FCS, MEM vitamins, $100 \mu \mathrm{g} / \mathrm{ml}$ streptomycin, and $100 \mathrm{U} / \mathrm{ml}$ penicillin and cultured at $37^{\circ} \mathrm{C}$ in humidified air with $10 \% \mathrm{CO}_{2}$ for a maximum of two passages.

Cell culture. Human chondrosarcoma cells, SW1353 (\# HTB94; American Type Culture Collection), were cultured in Ham's F-12/DMEM (1:1) supplemented with 10\% FCS, MEM vitamins, $100 \mu \mathrm{g} / \mathrm{ml}$ streptomycin, and $100 \mathrm{U} / \mathrm{ml}$ penicillin and cultured at $37^{\circ} \mathrm{C}$ in humidified air with $10 \%$ $\mathrm{CO}_{2}$. Peripheral blood mononuclear cells (PBMNC) were separated by leukapheresis of healthy donors followed by density gradient centrifugation over Ficoll/Hypaque. Isolated PBMNC were cultured in RPMI-1640 medium (PAN Biotech $\mathrm{GmbH}$, Aidenbach, Germany) in the presence of $2 \%$ human pooled AB-group serum and $5 \times 10^{-8} \mathrm{M} B$-mercaptoethanol supplemented with vitamins, sodium pyruvate, and nonessential amino acids (all from PAA Laboratories, Linz, Austria). For stimulation, cells were co-cultered with $100 \mathrm{ng} /$ $\mathrm{ml}$ LPS, $20 \mathrm{ng} / \mathrm{ml}$ PMA and $10 \mathrm{nM}$ ionomycin (all from SigmaAldrich, Deisenhofen, Germany). The murine macrophagelike cell line, RAW264.7, was cultured in RPMI-1640 medium under the conditions mentioned above. All cell lines were screened routinely for mycoplasma contaminations by an enzyme immunoassay according to the manufacturer's recommendation (Roche Diagnostics, Mannheim, Germany). Only mycoplasma-free cell lines were used. Human (h) recombinant (r) IL-10 as well as rhIL-6 were purchased from Peprotech Inc. (Rocky Hill, USA), whereas rhIL-1 $\alpha$ was provided by PAN Biotech $\mathrm{GmbH}$.

Stimulation experiments. For stimulation, $6.5 \times 10^{4}$ cells (SW1353 and primary chondrocytes) were seeded in 6-well plates until a confluency of $80 \%$ was reached. Afterwards, cells were stimulated with $10 \mathrm{U} / \mathrm{ml}$ rhIL-1 $\alpha$ for $24-48 \mathrm{~h}$. IL-10 was added $2 \mathrm{~h}$ prior to the start of IL-1 incubation. Murine macrophages, RAW264.7, seeded in 96-well plates were pretreated with $0-200 \mathrm{ng} / \mathrm{ml}$ rhIL-10 for $2 \mathrm{~h}$ and then stimulated with increasing concentrations of LPS (Sigma-Aldrich). After $24 \mathrm{~h}$, the medium was replaced by fresh medium containing IL-10 plus/minus LPS, and cells were incubated for a further $24 \mathrm{~h}$. At the end of each incubation period, supernatants were collected and stored at $-20^{\circ} \mathrm{C}$ until further analysis.

RNA extraction. Total cellular RNA was isolated using the RNeasy ${ }^{\circledR}$ spin column purification kit (Qiagen, Hilden, Germany). RNA concentrations were measured using the RiboGreen ${ }^{\circledR}$ RNA quantitation kit (Molecular Probes, Leiden, The Netherlands).

Reverse transcription and semi-quantitative PCR. Reverse transcription (RT) was performed with $750 \mathrm{ng}$ of total cellular RNA using the Superscript ${ }^{\mathrm{TM}}$ II RNase $\mathrm{H}^{-}$reverse transcriptase (Invitrogen, Karlsruhe, Germany) in a total volume of $20 \mu 1$. After initial heat inactivation for $10 \mathrm{~min}$ at $70^{\circ} \mathrm{C}$, first-strand cDNA synthesis was carried out with $500 \mathrm{ng}$ random primer and $200 \mathrm{U}_{\text {Superscript }}^{\mathrm{TM}} \mathrm{II}$ for $50 \mathrm{~min}$ at $37^{\circ} \mathrm{C}$ followed by heat inactivation at $70^{\circ} \mathrm{C}$ for $10 \mathrm{~min}$. PCR was performed in a total volume of $25 \mu \mathrm{l}$ using $50 \mathrm{pmol}$ of sense and antisense primers as given in Table I. After 15-min polymerase activation at $95^{\circ} \mathrm{C}$, the cDNA was amplified by $25-35$ cycles of $95^{\circ} \mathrm{C}$ for $1 \mathrm{~min}, 57-65^{\circ} \mathrm{C}$ for $1 \mathrm{~min}$, and $72^{\circ} \mathrm{C}$ for $1 \mathrm{~min}$ using the HotStarTaq $^{\mathrm{TM}}$ Master Mix kit (Qiagen), followed by a final extension period of $10 \mathrm{~min}$ at $72^{\circ} \mathrm{C}$. PCR products were resolved on $1.2 \%$ agarose gels and visualized by staining with ethidium bromide and UV transillumination.

Flow cytometry. For flow cytometry analysis, $1.5-2 \times 10^{5}$ cells were stained for $30 \mathrm{~min}$ at $0^{\circ} \mathrm{C}$ in the dark with $1 \mu \mathrm{g} / \mathrm{ml}$ of antiIL-10R1 (BD Biosciences PharMingen, Heidelberg, Germany) or anti-IL-10R2 (R\&D Systems, Wiesbaden, Germany). After washing, IL-10R2-labelled cells were incubated with biotinylated anti-mouse IgGs (1:500; Dianova, Hamburg, Germany) as secondary antibody and $1 \mu \mathrm{g} / \mathrm{ml}$ of phycoerythrin (PE)-labelled streptavidin (SA-PE; BD Biosciences) for $30 \mathrm{~min}$ each. IL-10R1-labelled cells were incubated with $1 \mu \mathrm{g} / \mathrm{ml}$ of FITC-conjugated anti-rat IgGs (BD Biosciences) for $30 \mathrm{~min}$. Surface expression was then measured in comparison to an isotype-matched control sample using a Coulter ${ }^{\circledR}$ Epics $^{\mathrm{TM}} \mathrm{XL}$ flow cytometer (Beckman Coulter GmbH, Krefeld, Germany). The fluorescence of 10,000 cells was collected on a 1024 channel 4 decades log scale through forward light scatter (FSC) and linear scale though right angle scatter (SSC). Analysis gates were set around debris and intact cells on FSC vs. SSC dot plot. The fluorescence histograms were generated using gated data. Data acquisition and analysis were performed automatically using EXPO ${ }^{\mathrm{TM}} 32$ ADC software (Beckman Coulter).

Cytokine and metalloproteinase assays. Concentrations of mouse or human IL-6 in the cell culture supernatants were evaluated by sandwich-ELISA measuring serial dilutions of supernatants from treated or untreated cells using the BD OptEIA $^{\mathrm{TM}}$ kit (BD Biosciences, Erembodegem, Belgium). Production of pro-MMP1 and pro-MMP13 was quantified by immunoassay using the corresponding Quantikine ${ }^{\circledR}$ ELISA kit purchased from R\&D Systems according to the manufacturer's recommendation. 
Table I. Primer sets, annealing temperatures, and cycle numbers used for polymerase chain reaction.

\begin{tabular}{llccc}
\hline Gene & \multicolumn{1}{c}{ Primers } & $\begin{array}{c}\text { Annealing } \\
\text { temperature }\left({ }^{\circ} \mathrm{C}\right)\end{array}$ & $\begin{array}{c}\text { RT-PCR } \\
\text { product (bp) }\end{array}$ & $\begin{array}{c}\text { No. of } \\
\text { cycles }\end{array}$ \\
\hline IL-10 & $\begin{array}{l}\text { f: GAC CCA GCC CCT TGA GAA ACC TTA TTG } \\
\text { r: GCC CCA AGC CCA GAG ACA AGA TAA AT }\end{array}$ & 60 & 359 & 35 \\
IL-10R1 & $\begin{array}{l}\text { f: GGG CCT TGC TGC TGG GGT CAT TTT TA } \\
\text { r: TGG GGC AGC AAA GTG AGG ATG TGA GT }\end{array}$ & 60 & 335 & 35 \\
IL-10R2 & $\begin{array}{l}\text { f: TGG CCT CGG TCT TCA TGG TCT G } \\
\text { r: CCC AGC CGA GTG TGT TTC CTT CT }\end{array}$ & 65 & 325 & 35 \\
GAPDH & $\begin{array}{l}\text { f: TTA GCA CCC CTG GCC AAG G } \\
\text { r: CTT ACT CCT TGG AGG CCA TG }\end{array}$ & 57 & 540 & 25 \\
\hline
\end{tabular}

f, forward; $r$, reverse.

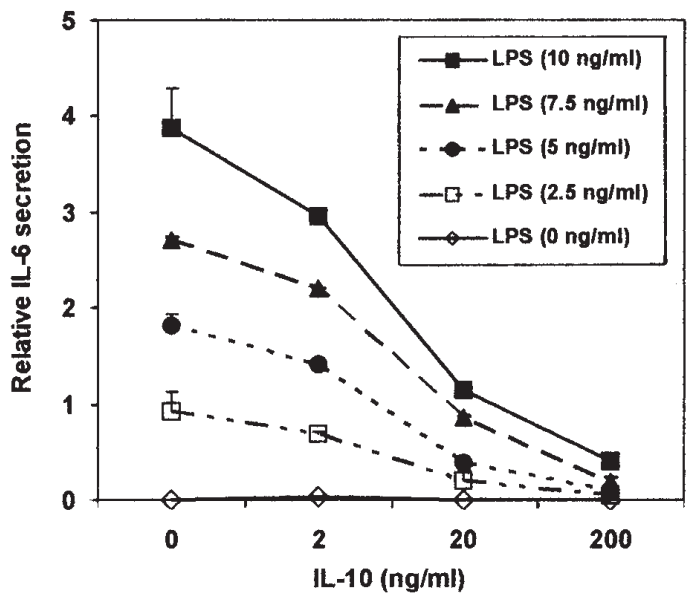

Figure 1. IL-10 down-regulates IL-6 release from stimulated murine macrophages. The murine macrophage-like cell line, RAW264.7, was stimulated for $24 \mathrm{~h}$ with different concentrations of LPS in the absence or presence of increasing concentrations of rhIL-10 as given in the figure. IL-10 incubation started $2 \mathrm{~h}$ prior to LPS stimulation. IL-6 release into the supernatant was determined by sandwich-ELISA. Data represent means \pm SEM from three separate experiments.

Phosphorylation of STAT3. SW1353 cells grown in $75-\mathrm{cm}^{2}$ culture flasks were starved overnight in RPMI-1640/HEPES pH 7.4 (1:1) without FCS. After short stimulation in the presence of rhIL-6 or rhIL-10 respectively, cells were lysed in $350 \mu 1$ lysis buffer consisting of $1.0 \%$ Nonidet P- $40,0.1 \%$ SDS, $10 \%$ glycerol, $250 \mathrm{mM} \mathrm{NaCl}, 1 \mathrm{mM}$ EDTA, $5 \mathrm{mM}$ DTT, $5 \mathrm{mM}$ p-nitrophenyl phosphate, $1 \mathrm{mM} \mathrm{Na} \mathrm{VO}_{4}, 10 \mathrm{mM} \mathrm{\beta}$ glycerophosphate, $1 \mathrm{mM}$ PMSF, $50 \mathrm{mM} \mathrm{NaF}, 10 \mu \mathrm{Na}_{2} \mathrm{MoO}_{4}$, Tris-HCl pH 6.8 supplemented with protease inhibitor mixture (Roche Diagnostics). The lysates were cleared by centrifugation (20 $\mathrm{min} ; 15,000 \mathrm{x} \mathrm{g}, 4^{\circ} \mathrm{C}$ ), and protein concentration was determined using the NanoOrange ${ }^{\circledR}$ protein quantitation kit (Molecular Probes). Proteins were solubilized for $10 \mathrm{~min}$ at $95^{\circ} \mathrm{C}$ in $30 \mu 1$ Laemmli buffer (16). Solubilized proteins were separated by $10 \%$ SDS-PAGE and blotted onto PVDF membranes (Macherey-Nagel, Düren, Germany). Specific proteins were detected by chemiluminescence using the ECL kit (Amersham Biosciences, Uppsala, Sweden) and antiSTAT3 and anti-phospho-STAT3 antibodies (Cell Signaling Technology, Beverly, USA).

Statistical analysis. Statistical differences between mean values were analyzed using the two-sided Student's t-test. Differences were considered as significant for $\mathrm{p}<0.05$.

\section{Results}

Prior to analysis of the effects of IL-10 on the expression of cartilage-degrading mediators, we tested the functionality of IL-10 in a suitable read out system. For this purpose, the effect of IL-10 on LPS-induced secretion of the proinflammatory cytokine, IL-6, was determined in the murine macrophage-like cell line, RAW264.7. As shown in Fig. 1, IL-10 was found to inhibit LPS-induced IL-6 secretion by RAW264.7 in a dose-dependent manner, thus confirming its biological activity.

Since the JAK/STAT pathway is the primary pathway known to be activated after the binding of IL- 10 to its corresponding receptor, we analyzed the effect of IL-10 on the IL-1-induced expression of distinct cartilage-degrading inflammatory mediators on the protein level which have been found to be regulated via activation of STAT3, one of the major transcription factors induced by IL-10 $(10,11)$. For these studies, the chondrosarcoma cell line, SW1353, was chosen as a model system for human chondrocytes. Firstly, we studied the effect of IL-10 on the IL-1-induced expression of the proinflammatory cytokine, IL-6. In contrast to previous findings on hematopoietic cells, IL-10 did not exert any inhibitory effect on IL-1-induced IL-6 secretion within $48 \mathrm{~h}$ of coincubation (Fig. 2A). From this result, we speculated that the concentration of IL-1 might be too high to detect a possible inhibitory effect of anti-inflammatory IL-10. Therefore, chondrocytes were stimulated with suboptimal concentrations of IL-1 in the presence of increasing concentrations of IL-10. Again, under these conditions, IL-10 did not reveal any suppressive action on IL-1-induced IL-6 secretion (Fig. 2B). 
A

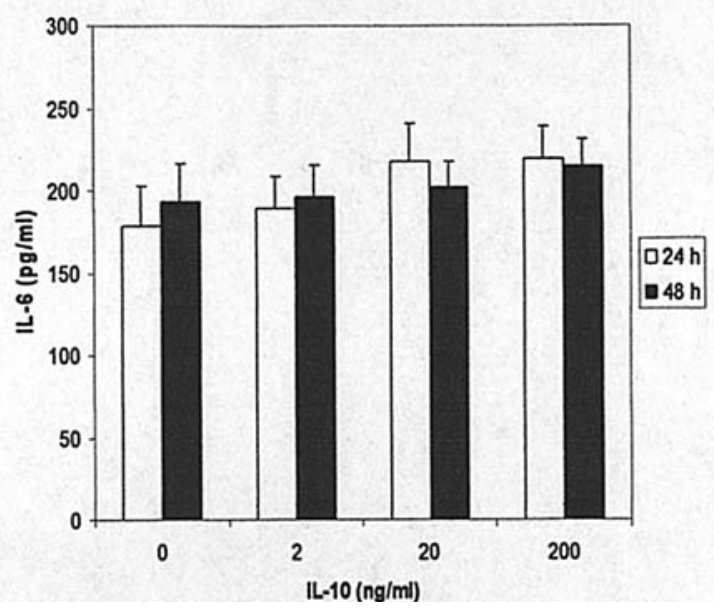

B

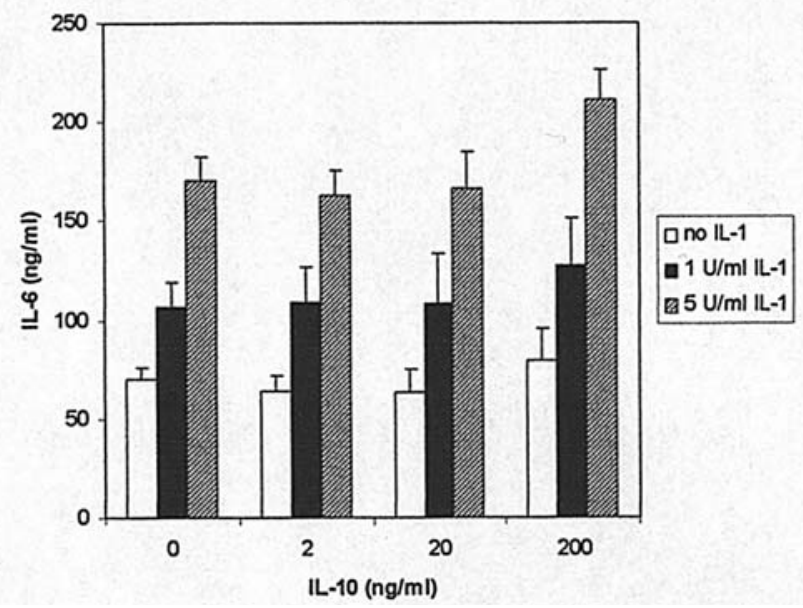

Figure 2. IL-10 does not affect IL-1-induced IL-6 secretion in human chondrocytic cells. Human chondrosarcoma cells, SW1353, were stimulated with 10 U/ml rhIL-1 $\alpha$ in a time-dependent manner in the absence or presence of increasing concentrations of rhIL-10 (A). IL-6 release was also tested in SW1353 cells costimulated with rhIL-10 and suboptimal concentrations of rhIL- $1 \alpha$ after $24 \mathrm{~h}$ in a dose-dependent manner (B). IL-6 release into the supernatant was determined by sandwich-ELISA. Data represent means \pm SEM from three separate experiments performed in triplicate and were corrected by the IL- 6 release observed after incubation with IL-10 alone.

Pro-MMP1 production

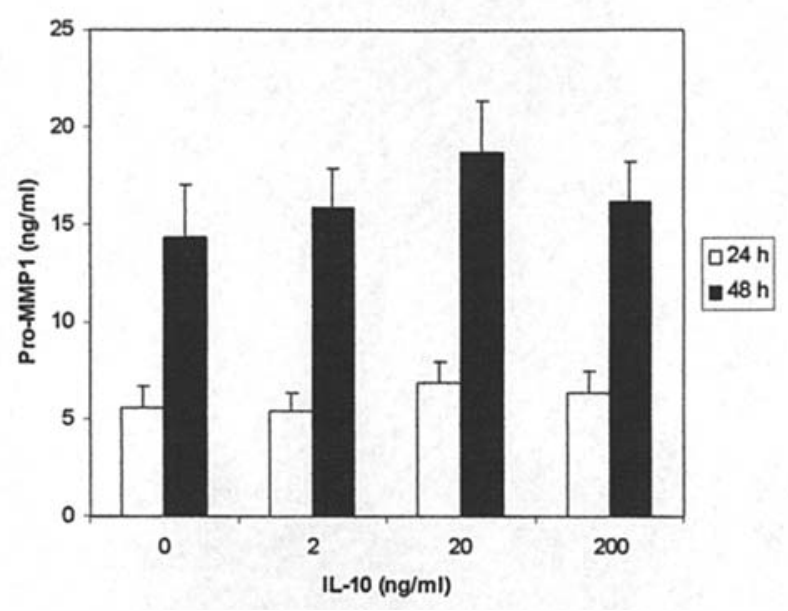

Pro-MMP13 production

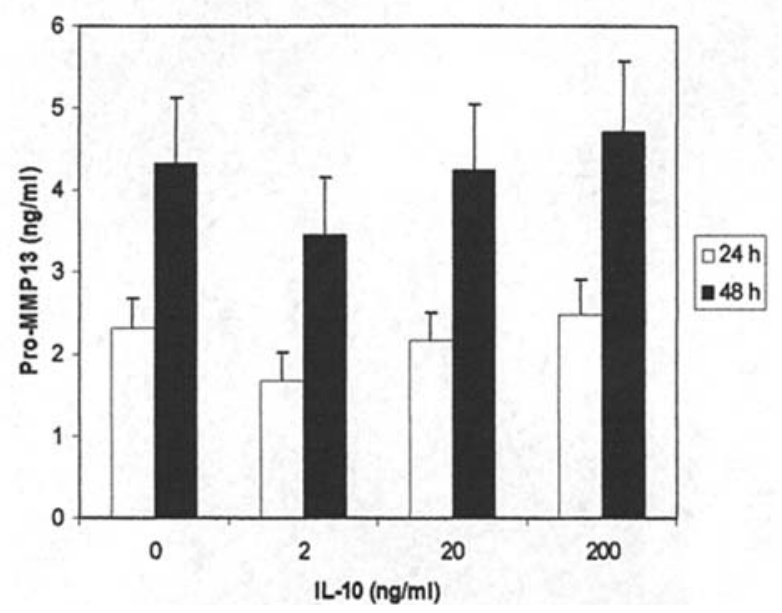

Figure 3. Failure of IL-10 in affecting IL-1-induced metalloproteinase production in human chondrocytic cells. SW1353 cells were co-incubated with 10 U/ml rhIL- $1 \alpha$ and increasing concentrations of rhIL-10 for 24 and $48 \mathrm{~h}$. Release of pro-MMP1 and pro-MMP13 was determined by sandwich-ELISA. Data represent means \pm SEM from three separate experiments performed in duplicate. Data were corrected by the spontaneous release of each MMP induced by IL-10 alone.

As a further example of STAT3-regulated inflammatory mediators induced by IL-1, we aimed to investigate the effect of IL-10 on the IL-1-induced production of cartilage destructive MMP1 (collagenase 1) and MMP13 (collagenase 3) in human chondrosarcoma cells. As demonstrated in Fig. 3, IL-10 did not antagonize the production of both, pro-MMP1 and proMMP13, in SW1353 cells.

In order to test whether this non-responsiveness might result from a defective phosphorylation of STAT3, we determined STAT3 phosphorylation in lysates of SW1353 cells after exposure to IL-10. As given in Fig. 4A, IL-10 did not induce phosphorylation of STAT3 within $30 \mathrm{~min}$ of exposure to the anti-inflammatory cytokine. This was not due to a defect in STAT3 because stimulation with IL-6 resulted in its maximum phosphorylation within 5 min, declining thereafter (Fig. 4B).

The IL-10 receptor complex is a heterotetramer consisting of two molecules of the IL-10R1 and two molecules of the IL-10R2 chain. Since the failure of IL-10 in phosphorylating STAT3 might be due to a deficient IL-10 receptor expression, we analyzed human primary chondrocytes from healthy donors and the human chondrocytic cell line, SW1353, with regard to the expression of several components of the IL-10 signaling complex. As a positive control, we used stimulated human PBMNC known to express several IL-10 family members. 


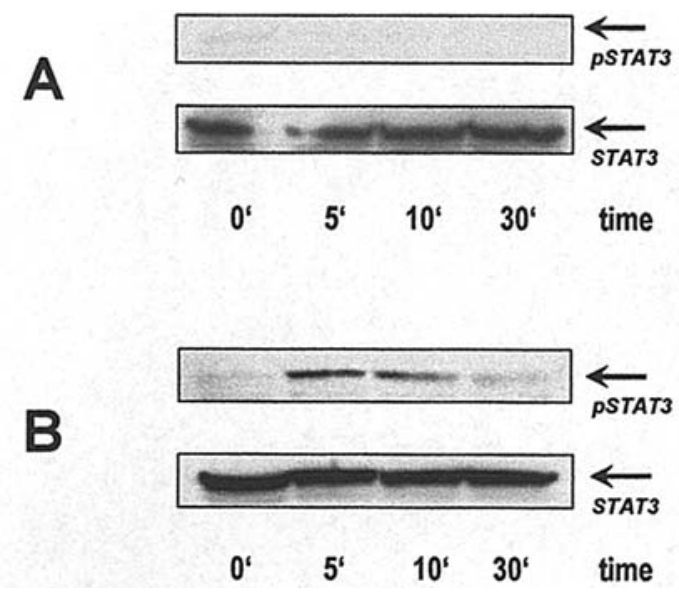

Figure 4. Failure of IL-10 in activating STAT3 in human chondrocytic cells. SW1353 cells were starved overnight and then stimulated with either $100 \mathrm{ng} /$ $\mathrm{ml}$ rhIL-10 (A) or $100 \mathrm{ng} / \mathrm{ml}$ rhIL-6 (B) for the indicated time points. After preparation of cell lysates, proteins were separated by $10 \%$ SDS-PAGE and visualized by Western blotting using anti-STAT3 and anti-phospho-STAT3 antibodies. The amount of protein applied was identical in each lane. Data show one representative experiment out of three. Please note that, in A, the exposition time of the phospho-STAT3 immunoblot is several times longer than that of STAT3

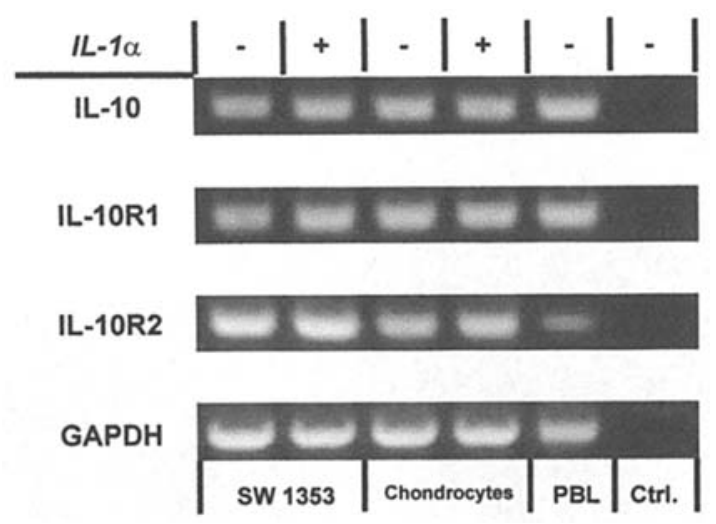

Figure 5. Expression of several members of the IL-10 family in human chondrocytic cells and PBMNC. Human chondrosarcoma cells, SW1353, and human primary chondrocytes from healthy donors were cultured in the presence or absence of $10 \mathrm{U} / \mathrm{ml}$ rhIL-1 $\alpha$ for $24 \mathrm{~h}$, whereas human PBMNC were co-stimulated with $100 \mathrm{ng} / \mathrm{ml} \mathrm{LPS}, 20 \mathrm{ng} / \mathrm{ml} \mathrm{PMA}$, and $10 \mathrm{nM}$ ionomycin for $4 \mathrm{~h}$. Total RNA was prepared and reverse transcribed followed by semi-quantitative RT-PCR and agarose gel electrophoresis. Data show one representative experiment out of four.

Using semi-quantitative RT-PCR, a constitutive expression of IL-10R1, IL-10R2, and IL-10 was found (Fig. 5). We additionally analyzed the expression of IL-10R1 and IL-10R2 on protein level by flow cytometry and observed a weak surface display of IL-10R2 in SW1353 cells (Fig. 6). As also shown in Fig. 6, we could not detect any surface expression of the ligand binding domain bearing IL-10R1.

\section{Discussion}

The aim of this study was to identify the molecular mechanisms of IL-10 actions on human chondrocytes. As a model system, the human chondrosarcoma cell line, SW1353, was chosen. SW1353 cells as well as other chondrocytic tumor cells,
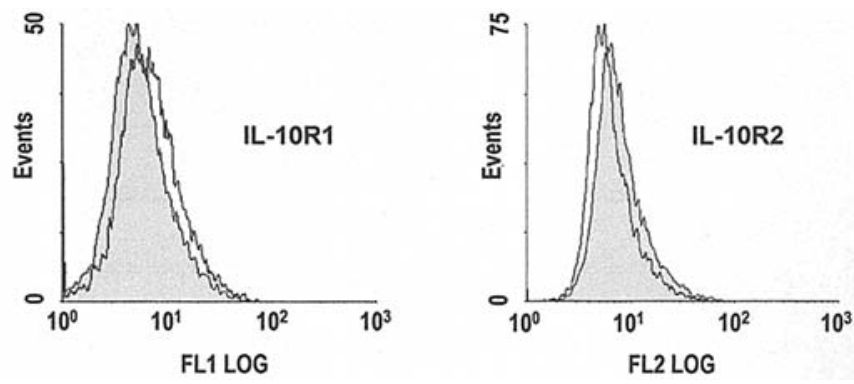

Figure 6. Flow cytometry analysis of IL-10R1 and IL-10R2. Human chondrosarcoma cells, SW1353, were stained with anti-IL-10R1 (left) or anti-IL-10R2 (right) as described in Materials and methods, and analyzed for surface expression of the corresponding antigens by flow cytometry. The white histogram represents the isotype-matched control; the grey histogram represents IL-10RI and IL-10R2-labelled cells, respectively. Data correspond to one characteristic experiment out of three.

including OUMS-27 and HCS-2/8, have been used in many studies as a reliable substitute for primary human chondrocytes. They represent a useful tool with which to investigate the expression of cartilage matrix proteins $(17,18)$, proinflammatory cytokines $(19,20)$, MMP $(19,21-24)$, TIMP (18) and chondrocytic transcription factor expression $(20,25,26)$. In a recent publication, comparison of SW1353 cells to primary chondrocytes was described with respect to their gene expression profile and IL-1 responsiveness (27). Although SW1353 were found to lack IL-1-induced expression of certain intracellular mediators such as leukemia inhibitory factor (LIF) and bone morphogenic protein-2 (BMP-2), similarities were seen with regard to the catabolic effects of IL-1, including MMP expression and IL-6 up-regulation. This renders SW1353 a suitable model system for human chondrocytes regarding the study of protease and pro-inflammatory cytokine induction mediated by IL-1 and the intracellular signaling pathways involved.

In the present study, we investigated the effect of IL-10 on the release of the pro-inflammatory cytokine, IL-6, after exposure to IL-1 in SW1353 cells. It is generally accepted that IL-1 is a potent inducer of IL-6 production in primary cells of articular tissue (28) and chondrosarcoma cells such as SW1353 $(19,20)$. Our data clearly demonstrated for the first time that IL-10 was unable to modulate the IL-1-induced IL-6 release from SW1353 cells. Moreover, the anti-inflammatory cytokine did not affect release of the pro-form of cartilagedegrading collagenase 1 (pro-MMP1) and collagenase 3 (proMMP13). MMP1 and MMP13 belong to the MMP family of closely related enzymes known to degrade several components of the extracellular matrix of articular cartilage in chronic inflammatory joint disorders. Among them, the expression of MMP1 as well as MMP13 is obviously regulated via STAT3 activation $(29,30)$. Our findings of a failure of IL-10 to affect the production of pro-MMP1 and pro-MMP13 in human chondrosarcoma cells after IL-1 treatment are in contrast to the previous observations of Wang and Lou (13) demonstrating a chondroprotective action of IL-10 by down-regulating the IL-1-induced MMP3 expression in rat chondrocytes. However, these data were raised at the mRNA level of a different molecule from a different species and can thus not be directly compared with regard to the protein expression pattern as in this study. 
IL-10 mediates its actions by binding to the corresponding IL-10 receptor complex (IL-10R). The IL-10R is a heterotetramer comprising two molecules of the specific IL-10R1 and two molecules of the common IL-10R2 (10,11). Ligand binding preferentially activates the JAK/STAT pathway leading to phosphorylation of the transcription factors, STAT1, STAT3, and STAT5 (31-33). As demonstrated in this study, exposure of SW1353 cells to IL-10 failed to induce phosphorylation of STAT3 while IL-6 was effective, showing that the STAT3 pathway in the chondrocytic cell line, SW1353, was intact. In a previous publication, unresponsiveness of human keratinocytes towards IL-10 that correlated with the lack of specific binding due to a deficient surface expression of IL-10R1 was observed (34). Our own results are in line with these findings, since we could not detect any surface expression of IL-10R1 in SW1353 cells, at least under the specific conditions used. Although IL-10R1 harbors the main ligand binding domain, IL-10R2 has been found to be essential for complete IL-10 responsiveness (35) recognizing a region of the IL-10 molecule (peptides 10-15 representing regions of helix $\mathrm{A}$ and the $\mathrm{AB}$ loop) neighboring or overlapping the site bound by IL-10R1 (36). However, IL-10R2 ligation alone does not allow the transduction of any IL-10 signal.

Our data indicate that the IL-10 unresponsiveness of human chondrosarcoma cells could be explained by the lack of functional IL-10 receptors due to a deficient IL-10R1 surface expression, suggesting that any IL-10 effects on human chondrocytes might be indirectly mediated. This hypothesis is supported by the fact that gene transfer of IL-10 into fibroblasts from RA patients nearly completely inhibited the invasion of fibroblasts into human cartilage after transplantation into SCID mice $(37,38)$. Thus, the chondroprotective effect of IL-10 observed in different animal and transplantation models of RA $(39,40)$ as well as in RA patients $(41)$ might be mediated by the modulation of infiltrating immune cells rather than the chondrocytes. Our observation of a failure of human chondrosarcoma cells to respond to IL-10 in conjunction with the above mentioned phenomena might be an explanation for the vulnerability of joint cartilage to inflammation. However, the results of this study should be critically re-evaluated in primary chondrocytes or cartilage explant cultures.

\section{Acknowledgements}

This work was supported by an intramural grant (ReForM C) from the University of Regensburg. The technical assistance of Daniela Vogl and Carolin Guhr is gratefully acknowledged. J.R. is supported by multimmune GmbH, Regensburg, Germany.

\section{References}

1. Curl WW, Krome J, Gordon ES, Rushing J, Smith BP and Poehling GG: Cartilage injuries: a review of 31,516 knee arthroscopies. Arthroscopy 13: 456-460, 1997.

2. Steadman JR, Rodkey WG, Briggs KK and Rodrigo JJ: The microfracture technique to treat full thickness articular cartilage defects of the knee. Orthopade 28: 26-32, 1999.

3. Steadman JR, Rodkey WG and Briggs KK: Microfracture to treat full-thickness chondral defects: surgical technique, rehabilitation, and outcomes. Am J Knee Surg 15: 170-176, 2003.

4. Bert JM: Abrasion arthroplasty. Oper Tech Orthop 4: 294-299, 1997.
5. Newman AP: Articular cartilage repair. Am J Sports Med 26: 309-324, 1998.

6. Garrett JC: Osteochondral allografts for reconstruction of articular defects of the knee. Instr Course Lect 47: 517-522, 1998.

7. Kish G, Modis L and Hangody L: Osteochondral mosaicplasty for the treatment of focal chondral and osteochondral lesions of the knee and talus in the athlete. Clin Sports Med 18: 45-66, 1999.

8. Minas T and Peterson L: Advanced techniques in autologous chondrocyte transplantation. Clin Sports Med 18: 13-16, 1999.

9. Minas T: The role of cartilage repair techniques, including chondrocyte transplantation, in focal chondral knee damage. Instr Course Lect 48: 629-643, 1999.

10. Grütz G: New insights into the molecular mechanism of interleukin-10-mediated immunosuppression. J Leukoc Biol 77: $3-15,2005$

11. Williams LM, Ricchetti G, Sarma U, Smallie T and Foxwell BM: Interleukin-10 suppression of myeloid cell activation - a continuing puzzle. Immunology 113: 281-292, 2004.

12. Lacraz S, Nicod LP, Chicheportiche R, Welgus HG and Dayer JM: IL-10 inhibits metalloproteinase and stimulates TIMP-1 production in human mononuclear phagocytes. J Clin Invest 96: 2304-2310, 1995.

13. Wang Y and Lou S: Direct protective effect of interleukin-10 on articular chondrocytes in vitro. Chin Med J (Engl) 114: 723-725, 2001.

14. Asadullah K, Sterry W and Volk HD: Interleukin-10 therapy review of a new approach. Pharmacol Rev 55: 241-269, 2003.

15. Islam S, Kermode T, Sultana D, et al: Expression profile of protein tyrosine kinase genes in human osteoarthritis chondrocytes. Osteoarthritis Cartilage 9: 684-693, 2001.

16. Laemmli UK: Cleavage of structural proteins during the assembly of the head of bacteriophage T4. Nature 227: 680-685, 1970.

17. Aida Y, Maeno M, Ito-Kato E, Suzuki N, Shiratsuchi H and Matsumura $\mathrm{H}$ : Effect of IL- $1 \alpha$ on the expression of cartilage matrix proteins in human chondrosarcoma cell line OUMS-27. Life Sci 75: 3173-3184, 2004.

18. Saas J, Gebauer M, Jacobi C, Haag J, Takigawa M and Aigner T: The human chondrosarcoma HCS-2/8 cell line is responsive to BMP-7, but not to IL-1beta. Front Biosci 10: 2027-2035, 2005.

19. Shi J, Schmitt-Talbot E, Di Mattia DA and Dullea RG: The differential effects of IL- 1 and TNF- $\alpha$ on proinflammatory cytokine and matrix metalloproteinase expression in human chondrosarcoma cells. Inflamm Res 53: 377-389, 2004.

20. Vincenti MP and Brinckerhoff CE: Early response genes induced in chondrocytes stimulated with the inflammatory cytokine interleukin-1beta. Arthritis Res 3: 381-388, 2001.

21. Liacini A, Sylvester J, Li WQ, Huang W, Dehnade F, Ahmad M and Zafarullah M: Induction of matrix metalloproteinase-13 gene expression by TNF- $\alpha$ is mediated by MAP kinases, AP-1, and NF- $\mathrm{KB}$ transcription factors in articular chondro-cytes. Exp Cell Res 288: 208-217, 2003.

22. Liacini A, Sylvester J, Li WQ and Zafarullah M: Mithramycin downregulates proinflammatory cytokine-induced matrix metalloproteinase gene expression in articular chondrocytes. Arthritis Res Ther 7: R777-R783, 2005.

23. Tardif G, Dupuis M, Reboul P, Geng CS, Pelletier JP, Ranger P and Martel-Pelletier J: Identification and differential expression of human collagenase-3 mRNA species derived from internal deletion, alternative splicing, and different polyadenylation and transcription initiation sites. Osteoarthritis Cartilage 11: 524-537, 2003.

24. Young DA, Lakey RL, Pennington CJ, et al: Histone deacetylase inhibitors modulate metalloproteinase gene expression in chondrocytes and block cartilage resorption. Arthritis Res Ther 7: R503-R512, 2005.

25. Schaefer JF, Millham ML, De Crombrugghe B and Buckbinder L: FGF signaling antagonizes cytokine-mediated repression of Sox9 in SW1353 chondrosarcoma cells. Osteoarthritis Cartilage 11: 233-241, 2003.

26. Tsuda M, Takahashi S, Takahashi Y and Asahara H: Transcriptional co-activators CREB-binding protein and $\mathrm{p} 300$ regulate chondrocyte-specific gene expression via association with Sox9. J Biol Chem 278: 27224-27229, 2003.

27. Gebauer M, Saas J, Sohler F, et al: Comparison of the chondrosarcoma cell line SW1353 with primary human adult articular chondrocytes with regard to their gene expression profile and reactivity to IL-1ß. Osteoarthritis Cartilage pp697-708, 2005. 
28. Guerne PA, Carson DA and Lotz M: IL-6 production by human articular chondrocytes. Modulation of its synthesis by cytokines, growth factors, and hormones in vitro. J Immunol 144: 499-505, 1990.

29. Catterall JB, Carrere S, Koshy PJ, et al: Synergistic induction of matrix metalloproteinase 1 by interleukin- $1 \alpha$ and oncostatin $M$ in human chondrocytes involves signal transducer and activator of transcription and activator protein 1 transcription factors via a novel mechanism. Arthritis Rheum 44: 2296-2310, 2001.

30. Rydziel S, Durant D and Canalis E: Platelet-derived growth factor induces collagenase 3 transcription in osteoblasts through the activator protein 1 complex. J Cell Physiol 184: 326-333, 2000.

31. Finbloom DS and Winestock KD: IL-10 induces the tyrosine phosphorylation of tyk 2 and Jak 1 and the differential assembly of STAT1 alpha and STAT3 complexes in human T cells and monocytes. J Immunol 155: 1079-1090, 1995.

32. Moore KW, De Waal MR, Coffman RL and O'Garra A: Interleukin-10 and the interleukin-10 receptor. Annu Rev Immunol 19: 683-765, 2001.

33. Wehinger J, Gouilleux F, Groner B, Finke J, Mertelsmann R and Weber-Nordt RM: IL-10 induces DNA binding activity of three STAT proteins (Stat1, Stat3, and Stat5) and their distinct combinatorial assembly in the promoters of selected genes. FEBS Lett 394: 365-370, 1996.

34. Seifert M, Gruenberg BH, Sabat R, et al: Keratinocyte unresponsiveness towards interleukin-10: lack of specific binding due to deficient IL-10 receptor 1 expression. Exp Dermatol 12: 137-144, 2003.
35. Spencer SD, Di Marco F, Hooley J, et al: The orphan receptor CRF2-4 is an essential subunit of the interleukin 10 receptor. J Exp Med 187: 571-578, 1998.

36. Wolk K, Witte E, Reineke U, et al: Is there an interaction between interleukin-10 and interleukin-22? Genes Immun 6: $8-18,2005$.

37. Müller-Ladner U, Evans CH, Franklin BN, Roberts CR, Gay RE, Robbins PD and Gay S: Gene transfer of cytokine inhibitors into human synovial fibroblasts in the SCID mouse model. Arthritis Rheum 42: 490-497, 1999.

38. Neumann E, Judex M, Kullmann F, et al: Inhibition of cartilage destruction by double gene transfer of IL-1Ra and IL-10 involves the activin pathway. Gene Ther 9: 1508-1519, 2002.

39. Joosten LA, Lubberts E, Durez P, Helsen MM, Jacobs MJ, Goldman $\mathrm{M}$ and van der Berg WB: Role of interleukin-4 and interleukin-10 in murine collagen-induced arthritis. Protective effect of interleukin-4 and interleukin-10 treatment on cartilage destruction. Arthritis Rheum 40: 249-260, 1997.

40. Jorgensen C, Apparailly F, Couret I, Canovas F, Jacquet C and Sany J: Interleukin-4 and interleukin-10 are chondroprotective and decrease mononuclear cell recruitment in human rheumatoid synovium in vivo. Immunology 93: 518-523, 1998.

41. Verhoef CM, van Roon JA, Vianen ME, Bijlsma JW and Lafeber FP: Interleukin 10 (IL-10), not IL-4 or interferon- $\gamma$ production, correlates with progression of joint destruction in rheumatoid arthritis. J Rheumatol 28: 1960-1966, 2001. 